\title{
Effect of Freezing and Thawing on the Discoloration of Tuna Meat
}

\author{
Chau-Jen Chow, ${ }^{* 1,2}$ Yoshihiro Ochiai, ${ }^{* 1}$ Shugo Watabe, ${ }^{* 1}$ \\ and Kanehisa Hashimoto*1
}

(Received September 28, 1987)

\begin{abstract}
Discoloration profiles of unfrozen or frozen and thawed ("frozen/thawed") meat of bluefin, yellowfin, and bigeye tunas during iced storage were examined, taking as parameters the metmyoglobin (metMb) to total $\mathrm{Mb}$ ratio (metMb\%), solubility (extractability) of $\mathrm{Mb}$, and Hunter color difference scale ( $\mathbf{L}, \mathbf{a}$, and $\mathbf{b}$ values).

During storage, metMb\% rapidly increased, while $\mathrm{Mb}$ solubility and a value remarkably decreased, $\mathbf{L}$ and $\mathbf{b}$ values tending to increase. Discoloration of frozen/thawed meat generally proceeded faster than that of unfrozen meat during iced storage, irrespective of tuna species. No significant differences in discoloration profile were observed among surface, middle and inner portions of dorsal meat, and ventral meat. Bigeye tuna meat showed a quite slow discoloration, even after freezing and thawing.

In the bluefin tuna meat which was pre-stored at $-20^{\circ} \sim-80^{\circ} \mathrm{C}$ for one month, followed by iced storage, the lower the pre-storage temperature was, the slower the rate of discoloration.
\end{abstract}

Frozen storage, especially at extremely low temperatures such as $-40^{\circ}$ and $-50^{\circ} \mathrm{C}$, effectively prevents the discoloration of tuna meat. ${ }^{1)}$ In this connection, it is empirically known that the frozen and thawed ("frozen/thawed") tuna meat discolors more quickly than unfrozen meat during subsequent iced storage. $\left.{ }^{2}, 3\right)$ However, no experimental data supporting this are available.

Discoloration of tuna meat during storage is usually followed, using as parameters the metmyoglobin (met $\mathrm{Mb}$ ) to total $\mathrm{Mb}$ ratio (metMb\%) in the meat extract. Evaluation of the discoloration in terms of metMb\% is objective, but rather troublesome and time-consuming. In addition, it neglects "insolubilized $\mathrm{Mb}$ " which is gradually formed even during frozen storage. In this connection, colorimetry using indexes such as Hunter color difference scale ${ }^{4)}$ has been successfully applied to evaluate the discoloration of agricultural products: e.g., beef, ${ }^{5)}$ egg yolk, ${ }^{\text {() }}$ potato chips and wine. ${ }^{7)}$ This useful technique, however, seems to have not fully been applied to tuna meat.

In this situation, frozen/thawed and unfrozen (control) tuna meat samples were stored in ice, and analyzed for met $\mathrm{Mb} \%$ and tristimulus values at due time intervals, and relationships among those parameters of discoloration discussed.

\section{Materials and Methods}

\section{Materials}

Fresh (unfrozen) specimens of bluefin tuna Thunnus thynnus, yellowfin tuna $T$. albacares, and bigeye tuna $T$. obesus, which were captured off the Sanriku Coast, Iwate Prefecture, were purchased. Only the ordinary muscle was used for storage experiments. In the case of bluefin tuna, adult and juvenile specimens (designated $\mathrm{A}$ and $\mathrm{B}$, respectively) were used.

\section{Storage Experiments}

Several portions of ordinary muscle were prepared. As shown in Fig. 1, the dorsal meat was excised from just above the lateral line, and divided into surface, middle, and inner portions. The three dorsal portions thus prepared, along with ventral meat, were cut into slices of about $8 \times 3 \times$ $0.8 \mathrm{~cm}$ and packed in vinyl chloride bags. These samples were divided into two groups. One group was stored in ice-water immediately, and the other was stored at $-20^{\circ} \mathrm{C}$ for 2 weeks in an airblast freezer. The latter group was then thawed in a water bath at $20^{\circ} \mathrm{C}$ and subsequently stored in ice-water. At intervals of 3-4 days, both

*1 Laboratory of Marine Biochemistry, Faculty of Agriculture, The University of Tokyo, Bunkyo, Tokyo 113 , Japan (周 照仁, 落合芳博, 渡部終五, 橋本周久: 東京大学農学部水産化学研究室).

*2 Present address: National Kaohsiung Institute of Marine Technology, Kaohsiung 800, Taiwan, R.O.C. 


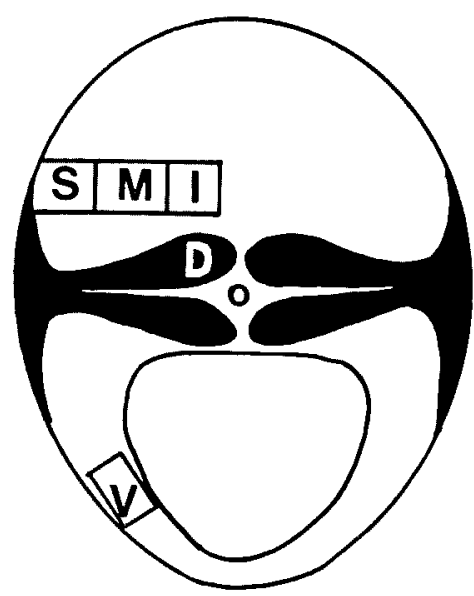

Fig. 1. Diagram of the cross section of tuna trunk muscle, showing the sampled portions for storage experiments.

groups were examined for the tristimulus values $(\mathbf{L}, \mathbf{a}, \mathbf{b})$ and met $\mathrm{Mb} \%$, as described below.

In addition, the inner portion of bluefin tuna meat was kept at $-80^{\circ} \mathrm{C}$ for two months, and then at $-20^{\circ},-30^{\circ},-40^{\circ}$, and $-80^{\circ} \mathrm{C}$, respectively, for one month. After thawing in a water bath at $20^{\circ} \mathrm{C}$, the samples were stored in ice water and measured for tristimulus values at due time intervals.

\section{Preparation of $M b$}

$\mathrm{Mb}$ was prepared by the method reported previously. ${ }^{8)}$ The $\mathrm{Mb}$ thus provided was highly pure, as demonstrated by isoelectric focusing. It was dissolved in and dialyzed against $50 \mathrm{~mm} \mathrm{Na-}$ phosphate buffer ( $\mathrm{pH} 6.0$ ), and to the solution was added $\mathrm{NaCl}$ to the final concentration of $0.1 \mathrm{M}$, just before a colorimetric measurement.

\section{Colorimetric Analysis}

Colorimetry was performed by a Nippon Denshoku ND-1001DP color difference meter and the results expressed as tristimulus values ( $L, \mathbf{a}$, and $\mathbf{b}$ ) of Hunter color difference scale. The instrument was set in the reflectance mode, and a white standard board $(\mathrm{X}, 92.6 ; \mathrm{Y}, 94.6 ; \mathrm{Z}$, 111.2) was used for calibration. The data were obtained on both sides of two samples and the mean values with standard deviation were figured out. In the case of $\mathrm{Mb}$ solution, transmission mode was applied, adjusting the instrument with another scale (X, 98.0; Y, 100.0; Z, 118.0), and the mean values of triplicate determinations were calculated.
Measurement of MetMb\%

The following operations were performed at around $0^{\circ} \mathrm{C}$. MetMb $\%$ in tuna meat was determined essentially according to the method of Sano and Hashimoto. ${ }^{9}$ The metMb\% of $\mathrm{Mb}$ solution was measured as reported previously. ${ }^{102}$ For the measurement of metMb\% in meat, the sample was ground in a mortar, and extracted with 2 volumes of ice-cold water for 3 min under bubbling with $\mathrm{CO}$ gas. After being neutralized with a few drops of $1 \mathrm{~N} \mathrm{NaOH}$, the extract was centrifuged at $17,000 \times \mathrm{g}$ for $10 \mathrm{~min}$. The supernatant was measured for absorbances at $568 \mathrm{~nm}$ before and after addition of hydrosulfite and ferricyanide, and metMb\% calculated.

\section{Measurement of Mb Solubility}

The color of a meat extract gradually faded with the lapse of storage time, due to a decrease of the intrinsic solubility of $\mathrm{Mb}$ or insolubilization of $\mathrm{Mb}$. To estimate the degree of insolubilization, the extract was treated with hydrosulfite and $\mathrm{CO}$ gas and measured for absorbance
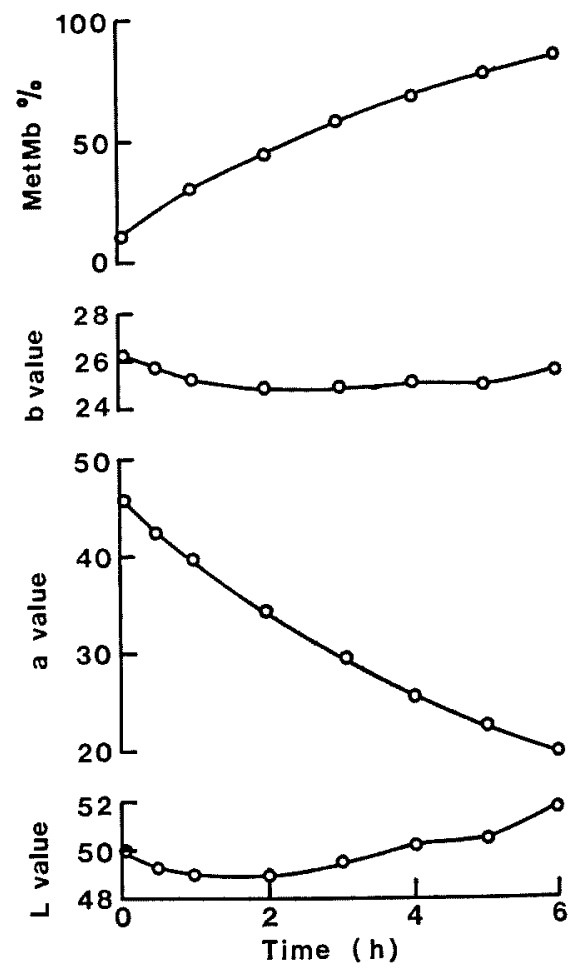

Fig. 2. Changes in tristimulus values $(\mathbf{L}, \mathbf{a}, \mathbf{b})$ and metMb\% of bluefin tuna $\mathrm{Mb}$ in $50 \mathrm{mM} \mathrm{Na-}$ phosphate buffer ( $\mathrm{pH} 6.0$ ) containing $0.1 \mathrm{M} \mathrm{NaCl}$ during incubation at $20^{\circ} \mathrm{C}$. $\mathrm{Mb}$ concentration: $1.1 \mathrm{mg} / \mathrm{m} l$. 

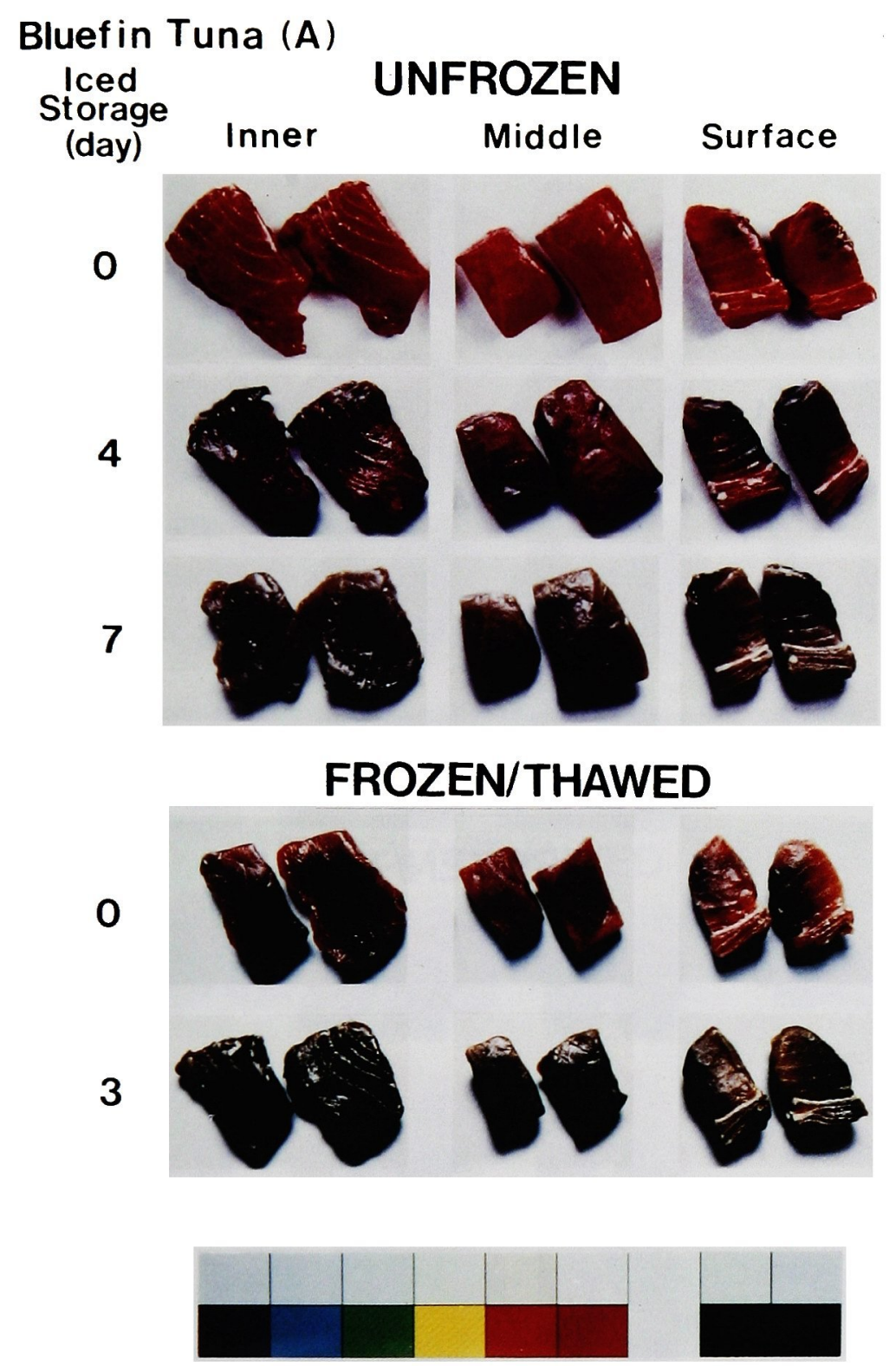

Fig. 3. Color changes in unfrozen and frozen/thawed bluefin tuna meat samples (specimen A) during iced storage. Inner, middle, and surface portions of dorsal meat were used. At the start, $\mathrm{K}$ value was $20.8 \%$ and $\mathrm{Mb}$ contents were 498,436 , and $1,020 \mathrm{mg} / 100 \mathrm{~g}$ for the inner, middle, and surface portions, respectively. Upper: unfrozen meat. Lower: frozen/ thawed meat which was stored at $-20^{\circ} \mathrm{C}$ for 2 weeks, thawed at $20^{\circ} \mathrm{C}$, and stored in ice. 


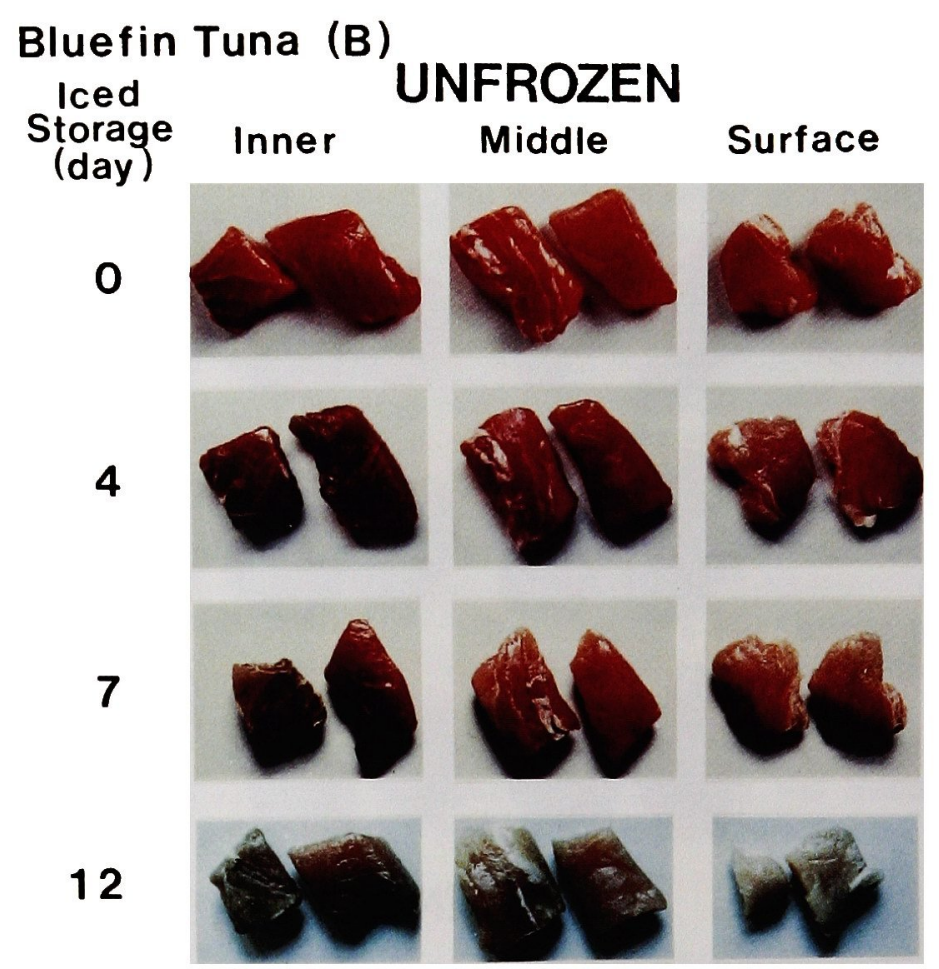

\section{FROZEN/THAWED}

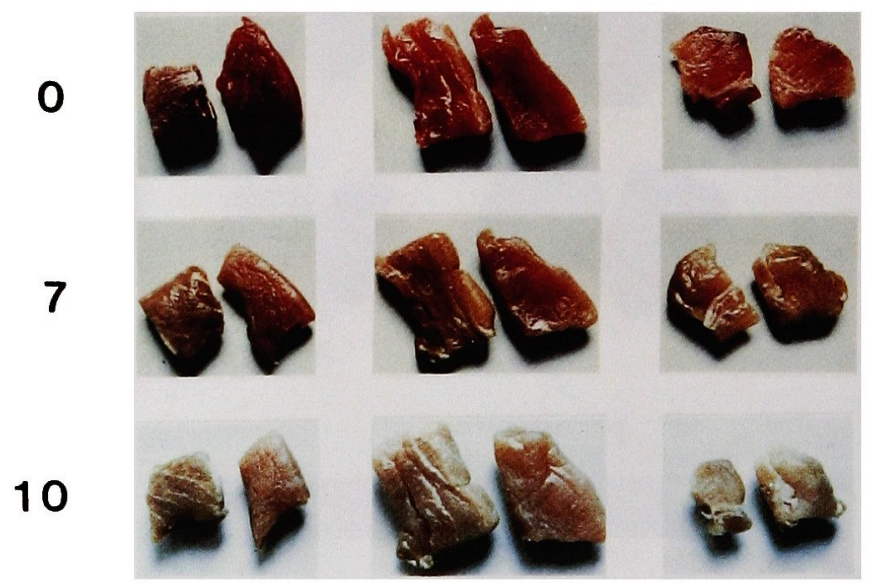

Fig. 4. Color changes in unfrozen and frozen/thawed bluefin tuna meat samples (specimen B) during iced storage. Inner, middle, and surface portions of dorsal meat were used. At the start, $\mathrm{K}$ value was $29.2 \%$, and $\mathrm{Mb}$ contents were 384,287 , and $224 \mathrm{mg} / 100 \mathrm{~g}$ for the inner, middle, and surface portions, respectively. Upper: unfrozen meat. Lower: frozen/thawed meat which was stored at $-20^{\circ} \mathrm{C}$ for 2 weeks, thawed at $20^{\circ} \mathrm{C}$, and stored in ice. 


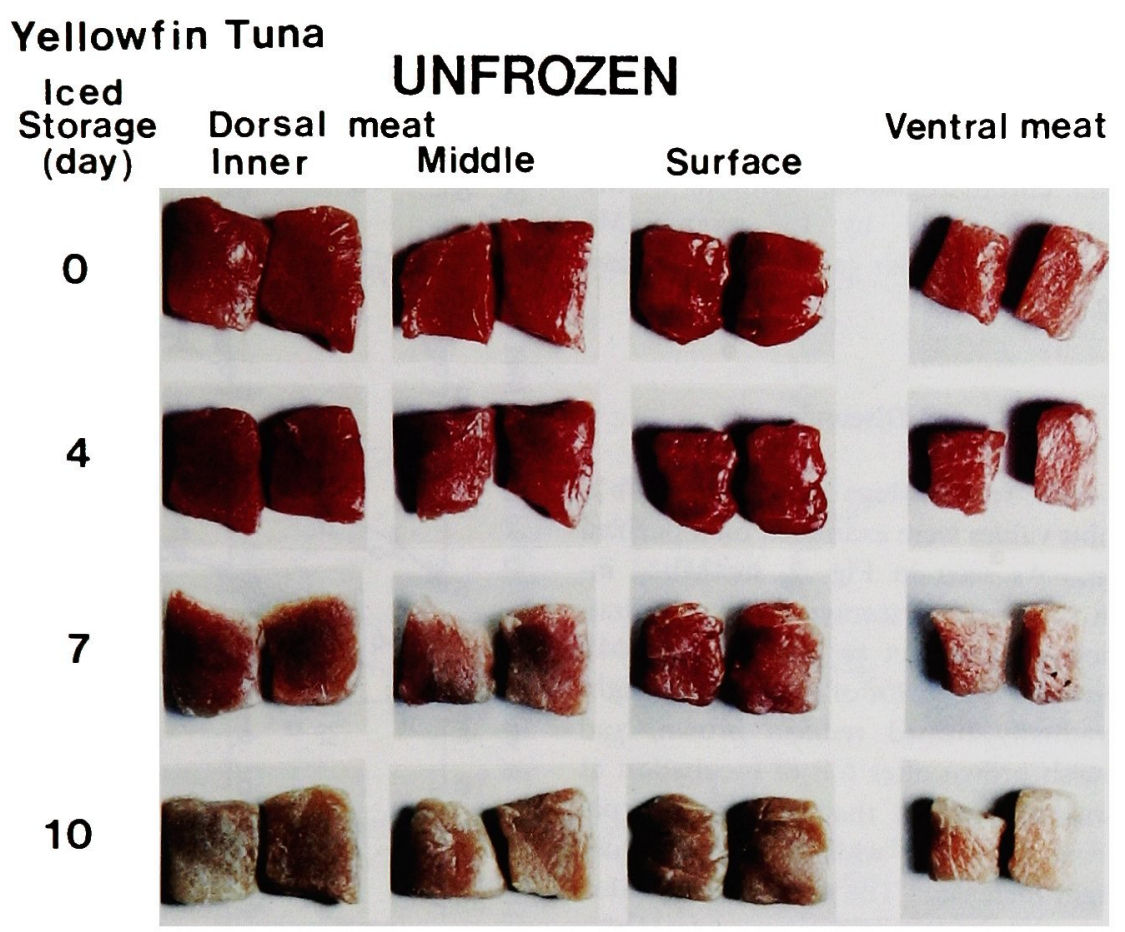

\section{FROZEN/THAWED}

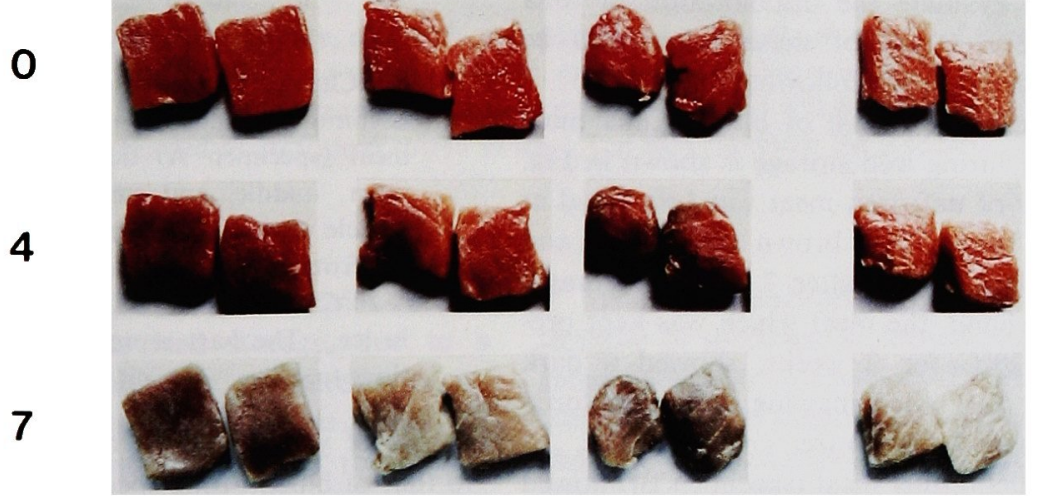

Fig. 5. Color changes in unfrozen and frozen/thawed yellowfin tuna meat samples during iced storage. Inner, middle, and surface portions of dorsal meat and ventral meat were used. At the start, $\mathrm{K}$ value was $28.9 \%$, and $\mathrm{Mb}$ contents were $147,160,183$, and $76 \mathrm{mg} / 100 \mathrm{~g}$ for the inner, middle, and surface portions of dorsal meat and ventral meat, respectively. Upper: unfrozen meat. Lower: frozen/thawed meat which was stored at $-20^{\circ} \mathrm{C}$ for 2 weeks, thawed at $20^{\circ} \mathrm{C}$, and stored in ice. 
at $568 \mathrm{~nm}$ and the decrement to original absorbance (as carbonylMb) was calculated and used as a parameter of "Mb solubility" $(\%)$.

\section{Other Analytical Methods}

$\mathrm{K}$ value (a freshness index of fish) was measured by a column chromatographic method. ${ }^{11}$ ) $\mathrm{Mb}$ content was determined by the cyanmetMb method, assuming the molar extinction coefficient to be $11,300 . .^{12}$

\section{Results and Discussion}

To begin with, relationships between met $\mathrm{Mb} \%$ and tristimulus values were examined on a purified $\mathrm{Mb}$ solution. As seen in Fig. 2, metMb\% increased with the lapse of storage time, as a firstorder reaction with respect to remaining oxy $\mathrm{Mb}$ (data not shown). The color of oxyMb was bright red, but gradually turned reddish brown, and finally yellowish brown after $6 \mathrm{~h}$ of incubation at $20^{\circ} \mathrm{C}$. It was also noted that a value sharply decreased from 45 to 20 , while $L$ and $b$ values showed a slight increase. The decrease of a value corresponded well to the increase of met $\mathrm{Mb} \%$, suggesting that a value might be used as a good parameter to evaluate the discoloration of tuna meat. The correlation of these values will be discussed in detail in the following paper. ${ }^{13 j}$

The discoloration profile of bluefin tuna meat (specimen A) during iced storage is shown in Fig. 3. The color of unfrozen meat was bright red at the start, but turned dark brown after 4 days and finally pale dark brown after 7 days of storage. On the other hand, the meat which was kept prefrozen at $-20^{\circ} \mathrm{C}$ for 2 weeks, showed a dark reddish color just after thawing, and discolored remarkably after 3 days in ice.

Another bluefin tuna meat (specimen B) showed a somewhat different pattern (Fig. 4). The color of unfrozen meat was light red at the start, probably due to a low Mb concentration. The meat did not given rise to off color even after 7 days, and still remained somewhat reddish after 12 days of storage. On the other hand, frozen/thawed meat was bright red at the start and turned yellowish red after 7 days of iced storage.

Discoloration profile of yellowfin tuna meat is shown in Fig. 5. The fresh meat was bright red at the start, but turned yellowish after 7 days and brownish yellow after 10 days. The frozen/ thawed meat showed similar but faster color changes during iced storage. The discoloration

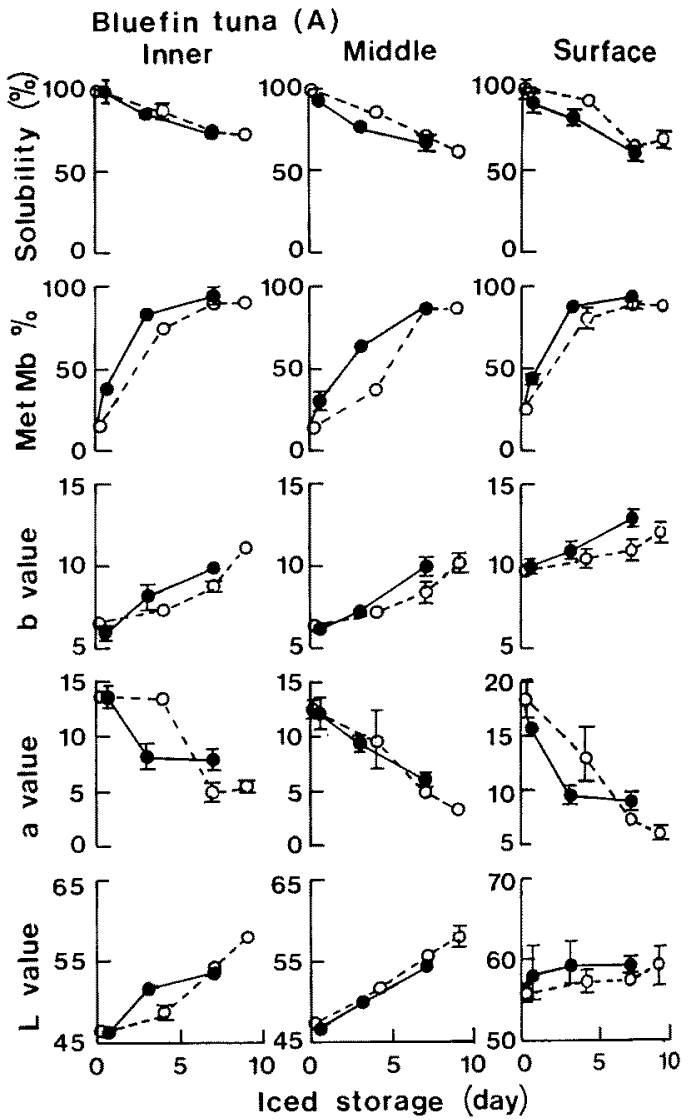

Fig. 6. Changes in Mb solubility, metMb\% and tristimulus values $(\mathbf{L}, \mathbf{a}$, and $\mathbf{b})$ of bluefin tuna meat (specimen A) during iced storage. The inner, middle, and surface portions of dorsal muscle were used. Symbols: 0 , unfrozen meat; - frozen/thawed meat which was stored at $-20^{\circ} \mathrm{C}$ for 2 weeks, thawed at $20^{\circ} \mathrm{C}$, and stored in ice. The bars represent the standard deviations $(n=4)$

profile of yellowfin tuna meat was rather similar to that of bluefin tuna specimen B.

In the next place, color changes of the tuna meat described above were examined colorimetrically. In Fig. 6 are shown the changes in tristimulus values of bluefin tuna specimen $\mathrm{A}$, along with the changes in $\mathrm{Mb}$ solubility and met $\mathrm{Mb} \%$. During iced storage, a value decreased gradually, while $\mathbf{b}$ and $\mathbf{L}$ values increased. The modes of change in tristimulus values were similar to those of $\mathrm{Mb}$ solution. However, the decrease of a value was smaller in meat than in $\mathrm{Mb}$ solution, while vice versa for $\mathbf{L}$ and a values. During storage, tuna meat tended to fade, in other words, to increase lightness. MetMb\% increased rather rapidly after 3-7 days of storage, attaining a 


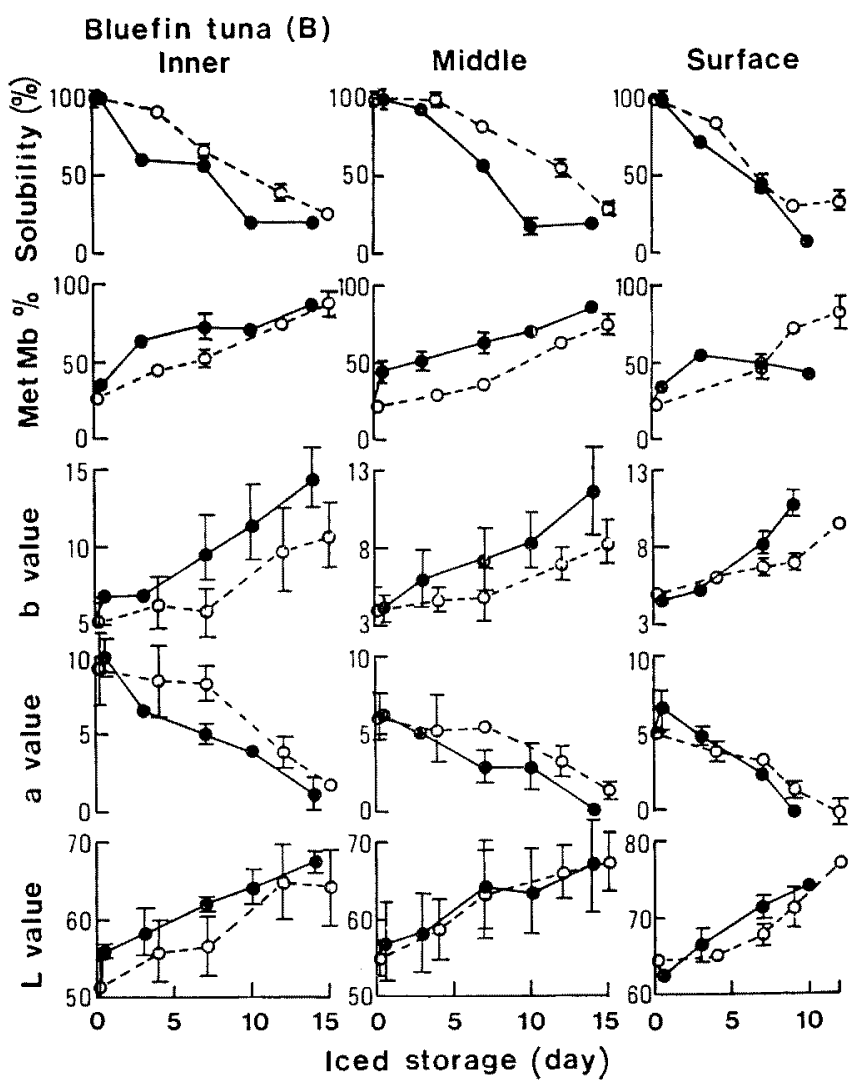

Fig. 7. Changes in $\mathrm{Mb}$ solubility, metMb\% and tristimulus values ( $\mathrm{L}$, $\mathbf{a}$, and $\mathbf{b}$ ) of bluefin tuna meat (specimen $\mathrm{B}$ ) during iced storage. Inner, middle, and surface portions of dorsal muscle were used. Symbols: $O$, unfrozen meat; , frozen/thawed meat which was stored at $-20^{\circ} \mathrm{C}$ for 2 weeks, thawed at $20^{\circ} \mathrm{C}$, and stored in ice. The bars represent the standard deviations $(n=4)$.

level around $90 \%$. The color of extract became paler gradually during iced storage, due to a decrease of $\mathrm{Mb}$ solubility or an increase of insolubilized $\mathrm{Mb}$. Actually, the relative amount of extractable $\mathrm{Mb}$ decreased from $100 \%$ to $60-70 \%$ after 9 days. Bito and Honma ${ }^{14)}$ reported that the amount of extracted $\mathrm{Mb}$ from bluefin tuna meat showed little change during 9 days of iced storage. The reason for the differences remains to be explained.

The changes in tristimulus values and metMb\% demonstrated that the discoloration was generally faster in frozen/thawed than in unfrozen meat. There were no significant differences among the surface, middle, and inner portions of dorsal meat.

Changes in tristimulus values, along with metMb\% and $\mathrm{Mb}$ solubility, of bluefin tuna specimen B during iced storage are shown in Fig.
7. The color changes were roughly resembling to those of specimen $A$, though the changes were generally slower in specimen $B$ than $A$, in agreement with their organoleptic differences (Figs. 3 and 4). The solubility of $\mathrm{Mb}$ decreased rapidly from $100 \%$ to $25 \%$ after $9-15$ days for unfrozen meat, and to $20 \%$ or less in 10 days for frozen/ thawed meat.

Color changes in yellowfin tuna meat were generally similar to those of bluefin tuna. Discoloration rate of frozen/thawed meat was also faster than that of unfrozen meat again, irrespective of sampled portion (Fig. 8).

Bito $^{15)}$ reported that there were no remarkable differences in discoloration pattern among dorsal, latero-ventral, and ventral meats of yellowfin, bigeye, and southern bluefin tunas during frozen storage at $-20^{\circ},-30^{\circ}$, and $-40^{\circ} \mathrm{C}$ for 6 months. In the present study as well, we observed no 


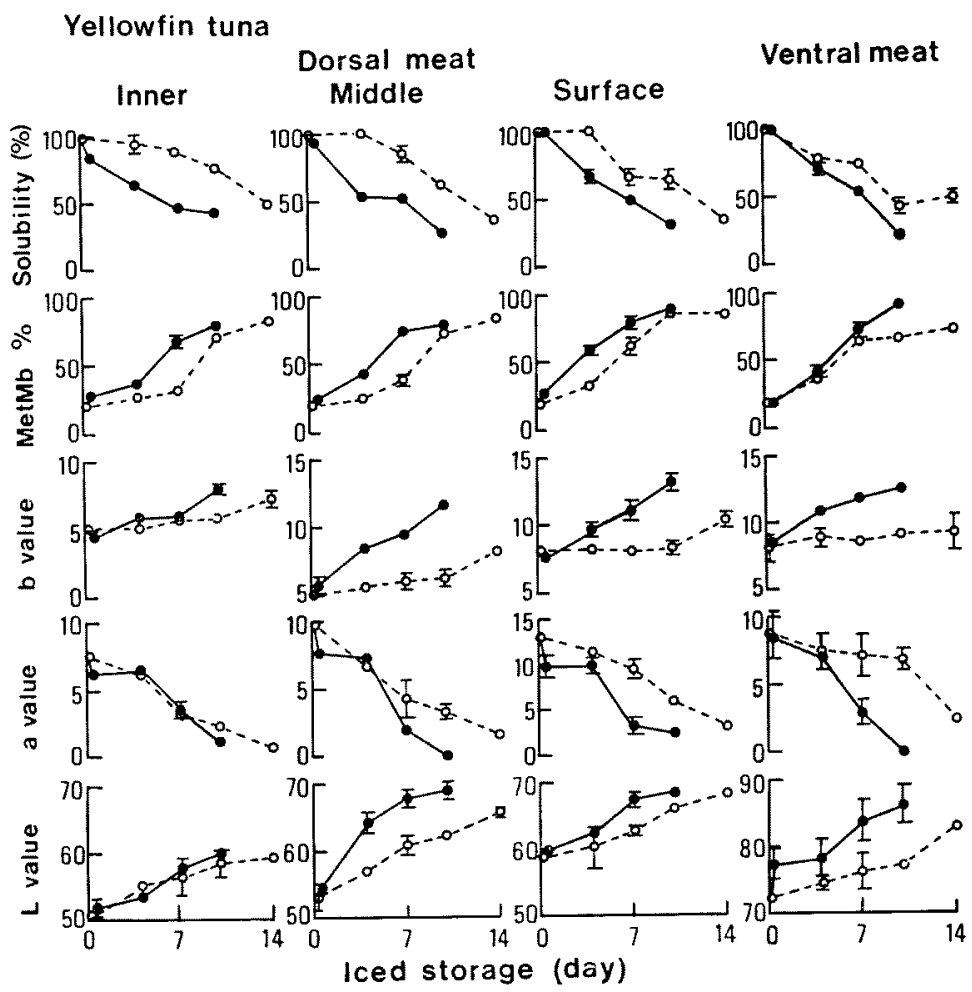

Fig. 8. Changes in $\mathrm{Mb}$ solubility, metMb\% and tristimulus values $(\mathrm{L}, \mathbf{a}, \mathbf{b})$ of yellowfin tuna meat during iced storage. Inner, middle, and surface portions of dorsal meat and ventral meat were used. Symbols: $O$, unfrozen meat; - frozen/thawed meat which was stored at $-20^{\circ} \mathrm{C}$ for 2 weeks, thawed at $20^{\circ} \mathrm{C}$, and stored in ice. The bars represent the standard deviations $(n=4)$.

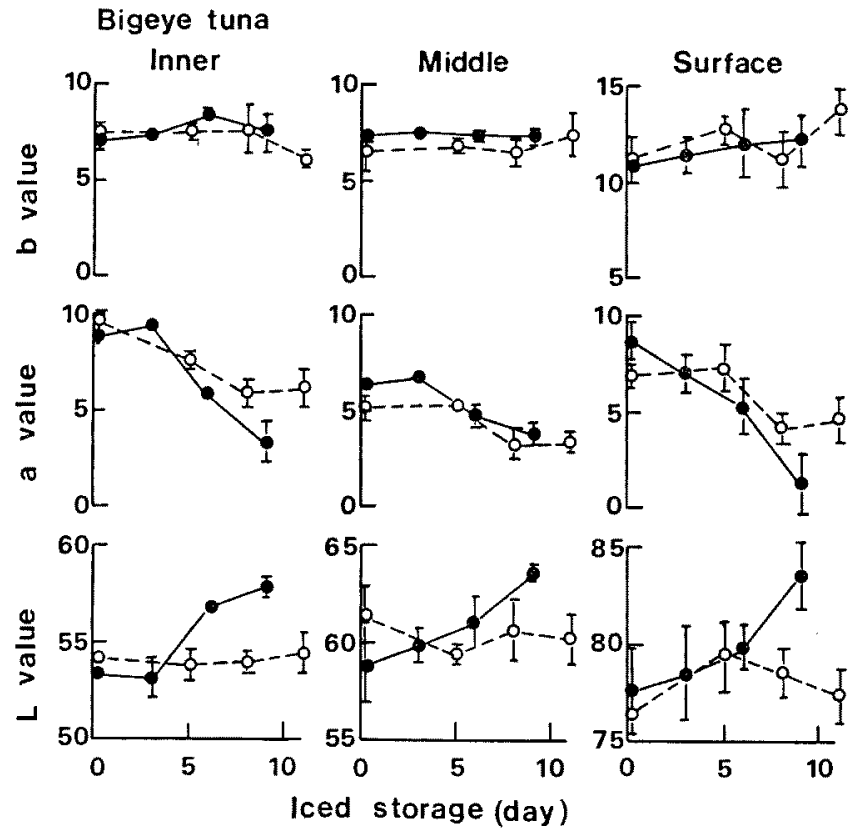

Fig. 9. Changes in tristimulus values $(\mathbf{L}, \mathbf{a}, \mathbf{b})$ of bigeye tuna meat during iced storage. Inner, middle and surface portions of dorsal meat were used. Symbols: $O$, unfrozen meat; $\bullet$, frozen/thawed meat which was stored at $-20^{\circ} \mathrm{C}$ for 2 weeks, thawed at $20^{\circ} \mathrm{C}$, and stored in ice. The bars represent the standard deviations $(n=4)$. 


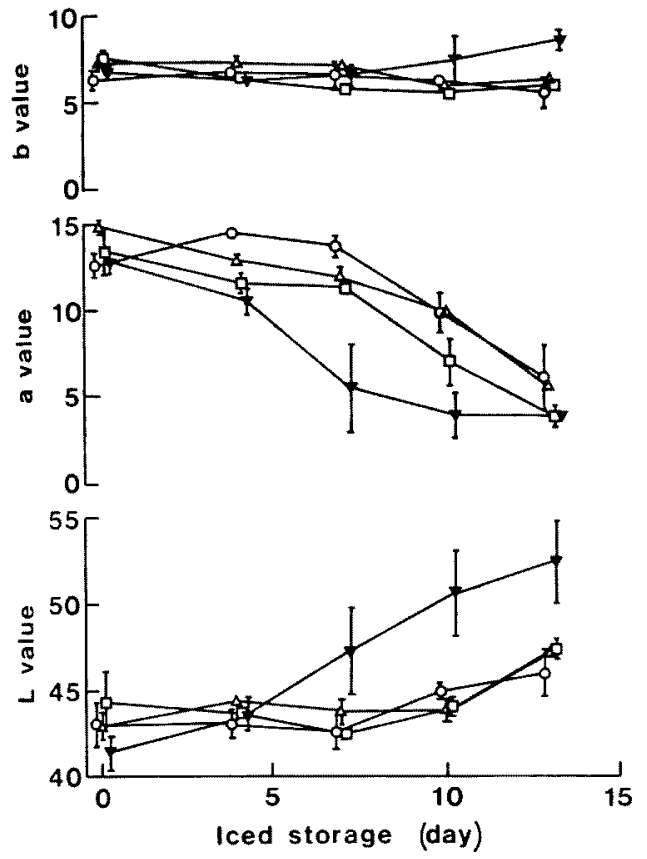

Fig. 10. Changes in tristimulus values $(\mathbf{L}, \mathbf{a}, \mathbf{b})$ of bluefin tuna meat during iced storage. Meat samples were pre-frozen at $-80^{\circ} \mathrm{C}$ for 2 months, followed by frozen storage at $-20^{\circ}(\nabla),-30^{\circ}$ $(\square),-40^{\circ}(\triangle)$, and $-80^{\circ} \mathrm{C}(\mathrm{O})$ for one month, thawed at $20^{\circ} \mathrm{C}$, and stored in ice. The bars represent the standard deviations $(n=4)$.

significant differences in discoloration profile among portions, whether unfrozen or frozen/ thawed meat from bluefin and yellowfin tunas.

Bito ${ }^{3)}$ and Tanaka et al. ${ }^{21}$ reported that yellowfin, bigeye, or southern bluefin tuna meat showed different patterns of discoloration when frozen/ thawed and then stored at $0^{\circ}$ and $2^{\circ} \mathrm{C}$. In the present study, the discoloration of bluefin tuna specimen A proceeded much more rapidly than that of specimen $\mathbf{B}$ and yellowfin tuna. These differences might be associated with their differences in metMb reducing activity ${ }^{18)}$ and/or oxygen consumption rate, which affect the autoxidation rate of $\mathrm{Mb}$ during iced storage. ${ }^{3)}$ Tanaka et al. ${ }^{2)}$ suggested that initial freshness of tuna meat affects the discoloration rate during storage. Therefore, this was not true for our bluefin tuna meat.

On the other hand, it was noted that bigeye tuna meat, whether unfrozen or frozen/thawed, discolored very slowly during iced storage (data not shown). However, changes in a value were quite similar to those of bluefin and yellowfin tuna meat
(Fig. 9). L value increased significantly in frozen/ thawed meat, although the increment was small compared to other tuna meat. b values maintained the initial levels, whether the meat was unfrozen or frozen/thawed.

In order to examine the effect of pre-storage temperature on discoloration profile, some bluefin tuna meat samples were stored at $-80^{\circ} \mathrm{C}$ for 2 months, followed by storage at $-20^{\circ},-30^{\circ},-40^{\circ}$, and $-80^{\circ} \mathrm{C}$ for one more month. After thawing at $20^{\circ} \mathrm{C}$, they were stored in ice, and their changes in color followed by tristimulus values. As seen in Fig. 10, the meat sample stored at $-20^{\circ} \mathrm{C}$ discolored most quickly. The lower the storage temperature was, the slower the changes of tristimulus values.

Yamanaka et al. ${ }^{18)}$ reported similar results on discoloration patterns of bigeye tuna meat, with reference to remaining met $\mathrm{Mb}$ reductase activity. Hashimoto and Watabe ${ }^{17)}$ examined discoloration profiles of bigeye tuna meat during frozen storage at several temperatures. When the meat which had been kept at $-50^{\circ} \sim-55^{\circ} \mathrm{C}$ for 3 months were stored at $-20^{\circ},-40^{\circ},-60^{\circ}$, and $-80^{\circ} \mathrm{C}$ for one year, the $-20^{\circ} \mathrm{C}$ meat specimen showed a clearly faster discoloration than all other specimens. The present result, along with theirs, suggested that the discoloration of tuna meat proceeds steadily during storage at $-20^{\circ} \mathrm{C}$, and is accelerated during iced storage after thawing. It was also demonstrated that the frozen storage of tuna meat at temperatures below $-30^{\circ} \mathrm{C}$ can effectively prevent the accelerated discoloration after thawing.

From the above results, it was concluded that frozen/thawed meat discolors faster than unfrozen meat irrespective of tuna species, and that the discoloration rate of tuna meat after thawing was dependent upon the pre-freezing temperature. Further studies are now in progress to elucidate the mechanism(s) involved.

\section{Acknowledgements}

This study was supported in part by a Grantin-Aid from the Ministry of Education, Science and Culture of Japan.

\section{References}

1) M. Bito: Nippon Suisan Gakkaishi, 31, 534-539 (1965).

2) T. Tanaka, K. Nishiwaki, K. Kakuda, and T. 
Tomimatsu: Trans. Japan. Assoc. Refrig., 1(2), 71-81 (1984).

3) M. Bito: Refrigeration, 48, 846-852 (1973).

4) R. S. Hunter: J. Opt. Soc. Am., 48, 985-995 (1958).

5) H. E. Synder: J. Food Sci., 29, 535-539 (1964).

6) T. Philip, C. W. Weber, and J. W. Berry: Food Technol., 30(10), 58-59 (1976).

7) A. C. Little: Food Technol., 30(10), 74-82(1976).

8) C.-J. Chow, Y. Ochiai, and K. Hashimoto: Nippon Suisan Gakkaishi, 51, 2073-2078 (1985).

9) Y. Sano and K. Hashimoto: Nippon Suisan Gakkaishi, 24, 519-523 (1958).

10) C.-J. Chow, Y. Ochiai, S. Watabe, and K. Hashimoto: J. Food Sci., 52, 589-591 (1987).
11) H. Uchiyama and K. Kakuda: Nippon Suisan Gakkaishi, 50, 263-267 (1984).

12) D. L. Drabkin: Am. J. Med. Sci., 209, 268-270 (1945).

13) Y. Ochiai, C.-J. Chow, S. Watabe, and K. Hashimoto: Nippon Suisan Gakkaishi, 54, 649653 (1988).

14) M. Bito and S. Honma: Nippon Suisan Gakkaishi, 33, 33-40 (1967).

15) M. Bito: Bull. Tokai Reg. Fish. Res. Lab., No. 103, 73-82 (1980).

16) H. Yamanaka, M. Takamizawa, and K. Amano: Nippon Suisan Gakkaishi, 39, 631-637 (1973).

17) K. Hashimoto and S. Watabe: Nippon Suisan Gakkaishi, 49, 203-206 (1983). 